\title{
Numerical Validation of Frictional Coefficient for a Flat Plate with Various Anti-Fouling Coatings
}

\author{
K Abhiroop, B.M. Shameem
}

\begin{abstract}
Skin friction is responsible for approximately 60-70\% of ship resistance. The fuel consumption and emission of the ship vary with the wetted surface, hull form and roughness. Reducing wetted surface area is not feasible and hence for reducing frictional resistance either the hull form should be optimized or the hull roughness function be made optimum. Most of the cases the hull form optimization of existing vessels are difficult and not economical. For these ships, the application of anti-fouling coating or air injection method below the bottom of the hull can be easily adapted to minimize the frictional resistance without any alteration on the vessel. The anti-fouling coating reduces the accumulation of marine growth and surface deterioration and hence limit the frictional drag. The selection of anti-fouling coating is also important since the resistance generated by the surrounded fluid on the ship increases with an increase in roughness function. This paper presents the numerical analysis and validation of frictional coefficient using CFD for different anti-fouling coating in the case of a flat plate. The roughness effects of different marine coatings are replicated and the frictional coefficient are compared with existing experimental data. The CFD results are agreeable with the published results. The work presented here could be applied to ship hulls to study the roughness effects due to various coatings or bio-fouling conditions to estimate the frictional drag and its effects in fuel consumption.
\end{abstract}

Keywords: Roughness, CFD, frictional coefficient, anti-fouling coating

\section{INTRODUCTION}

Reduction in frictional resistance improves the fuel consumption and reduction in $\mathrm{CO}_{2}$ emissions worldwide. The regulations, such as the Energy Efficiency Design Index (EEDI) [1], Ship Energy Efficiency Management Plan (SEEMP) [2], and the recommended practices such as the Energy Efficiency Operational Indicator (EEOI) [3] have been implemented in recent times to limit the harmful gases that are released to the marine environment from ships. It was reported one decade ago, the quantity of $\mathrm{CO}_{2}$ released from the shipping industry is about 870 million tons. This is equivalent to $2.7 \%$ of the total $\mathrm{CO}_{2}$ emissions [4]. Since then the $\mathrm{CO}_{2}$ emissions from ships are increasing [4]. The International Maritime Organization (IMO) has therefore

Revised Manuscript Received on November 15, 2019

* Correspondence Author

K. Abhiroop, Naval Architecture and Offshore Engineering, AMET Deemed to be University, Chennai, India.

Dr.B.M. Shameem*, Naval Architecture and Offshore Engineering, AMET Deemed to be University, Chennai, India. been forced to devise and implement energy efficiency and GHG (Greenhouse Gases) regulations.

Skin friction accounts for the majority of the total resistance (approximately $60 \%-70 \%$ ) for most of the large commercial vessels [5]. To minimize the wave-making resistance, the shape of the hull is optimized according to the operational speed and main characteristics of the hull. The frictional drag can be account on the hull around $90 \%$ of the total drag on some hull type [6]. In slow speed ships such as oil tankers, frictional resistance is nearly $80 \%$ percent of the total resistance while it is about $50 \%$ at high speed ships such as container vessels [7]. One of the cause for the increase in the frictional resistance is the formation of micro-organisms on the ship hull and improper selection of anti-fouling (AF) coatings.

Micro fouling develops rapidly on ship hulls, and worse, several biofilms persist under even the strongest AF coatings [8]. This create increased surface roughness, frictional resistance, and fuel consumption [6]. According to [9], the increase in resistance due to the presence of micro-organisms are nearly $2 \%$ and hard shelled organisms contributes in increase in resistance upto about $40 \%$. The effect of fouling on shaft power is studied for a frigate vessel at a speed of 15 knots and found that the presence of slime alone caused a $21 \%$ increase in shaft power [10]. Meanwhile, heavy calcareous fouling led to an $86 \%$ increase in shaft power requirements. It is reported about $66 \%$ increase in resistance with $5 \%$ coverage of shell fouling [11], [6]. However the effect of artificial slime and microbial slime is reported to be below $20 \%$ for flat plate [12].

The experimental results using flat plates in order to investigate the frictional resistance characteristics of different anti-fouling surfaces was reported by [13]. The selection of the coating would affect the resistance coefficient. Colebrook type of wall function is used [14], to predict the frictional component of resistance. The prediction of roughness effects of antifouling coating require high computing facility, for capturing the small variations in the surface due to the application of different anti-fouling coatings. This could be in the order of micrometers $(\mu \mathrm{m})$ [15]. There are attempts made to reproduce the surface roughness using CFD technique [16]. More studies needs to be performed to accomplish the usage of CFD in predict the roughness as well as the bio fouling conditions in plate and further to apply in ship hulls. The objective of the present study is to validate the roughness conditions due to different anti-fouling coatings with the published experimental data. 


\section{NUMERICAL METHOD}

\section{A. RANS Mathematical Formulation}

The simulation is modelled with free surface to replicate the experimental setup given in [13]. The literature discussed the effect of anti-fouling coatings on the flat plate using experiment to estimate the effect of roughness on frictional drag. The governing equation for the present work is the Unsteady Reynolds-Averaged Navier-Stokes (URANS), which computes pressure and velocity to estimate the total resistance, shear and pressure component due to the fluid flow. The Shear Stress Transport (SST) k- $\omega$ turbulence model is used to predict the turbulence which combines the $\mathrm{k}-\varepsilon$ and $\mathrm{k}-\omega$ model, the former model computes the near the wall effect and the later for capturing far field turbulence. For all simulation cases, the Courant-Frederich-Lewis (CFL) number is maintained less than unity to ensure numerical stability [17].

\section{B. Roughness Function}

The roughness condition on the surface of flat plate is verified theoretically using the roughness function $\Delta \mathrm{U}^{+}$and roughness Reynolds number, $\mathrm{k}^{+}[18]$. The value of $\mathrm{k}^{+,}$and $\Delta \mathrm{U}^{+}$for the flat plate is obtained iteratively using "Eq. (1)" and "Eq. (2)" as given in [19], where the value of frictional drag coefficient, $\mathrm{C}_{\mathrm{F}}$ is obtained from the experiment results given in [25].

$$
\begin{aligned}
& k^{+}=\left(\frac{k}{L}\right)\left(\frac{R_{e} C_{F}}{2}\right)\left(\sqrt{\frac{2}{C_{F}}}\right)_{R}\left[1-\frac{1}{\kappa}\left(\sqrt{\frac{C_{F}}{2}}\right)_{R}+\frac{1}{\kappa}\left(\frac{3}{2 \kappa}-\Delta U^{+\prime}\right)\left(\frac{C_{F}}{2}\right)_{2}\right] \\
& \Delta U^{+}=\left(\sqrt{\frac{2}{C_{F}}}\right)_{S}-\left(\sqrt{\frac{2}{C_{F}}}\right)_{R}-19.7\left[\left(\sqrt{\frac{C_{F}}{2}}\right)_{S}-\left(\sqrt{\frac{C_{F}}{2}}\right)_{R}\right]-\frac{1}{\kappa} \Delta U^{+}\left(\sqrt{\frac{C_{F}}{2}}\right)_{R}
\end{aligned}
$$

$L$, length of plate, $R_{e}$, Reynolds number, $\Delta U^{+}$, roughness function slope, $k$, roughness height and $\kappa$ is von Karman constant taken to be 0.42 as suggested by [20], subscript $S$ indicates smooth condition and $R$ indicates rough condition.

The present paper focuses on the un-fouled condition with five antifouling coating viz., Silicone 1, Silicone 2, Ablative Copper, SPC (Self-Polishing Copolymer) Copper and SPC TBT (Tributyltin) and one sand paper case, 60-grit SP. The surface roughness of the different test surface are considered from [17]. The simulations are carried for three different cases of Reynolds number, Case $1-\operatorname{Re}=2.8 \times 10^{6}$, Case $2-$ $\operatorname{Re}=4.2 \times 10^{6}$, and Case $3-\operatorname{Re}=5.5 \times 10^{6}$. For regenerating the actual roughness condition in the numerical setup, it is suggested to choose the roughness height, $k$ for antifouling surface as $0.17 R_{a}$ for un-fouled conditions $0.75 R_{t}$ for sand paper roughness.

\section{Geometry and Boundary Condition}

The dimensions of the flat is shown in Fig.1. The free surface is $0.59 \mathrm{~m}$ from the bottom of the plate. No-slip boundary condition is imposed on the plates to represent zero velocity on the surface of the plate. The extension of the domain chosen for the work is given in "Fig. 2(a)" and "Fig. 2(b)". The different boundary conditions imposed on the overall domain is shown in "Fig.3".

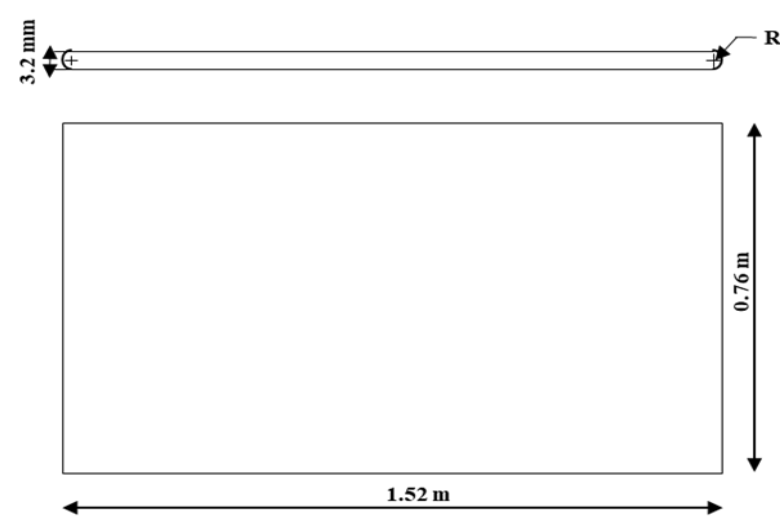

Fig. 1. Dimensions of flat plate (top and profile view)

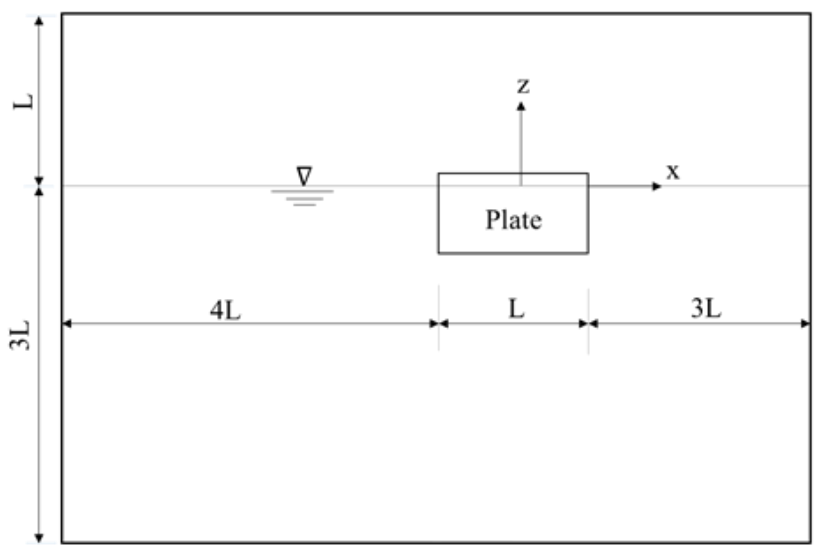

Fig. 2 (a). Extension of computational domain (Side view)

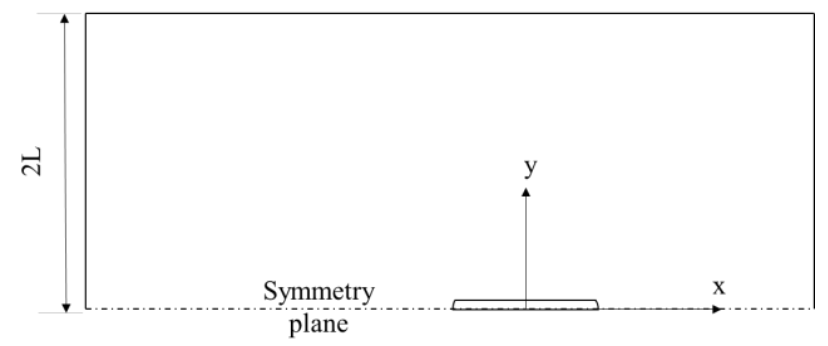

Fig. 2 (b). Extension of computational domain (Top view)

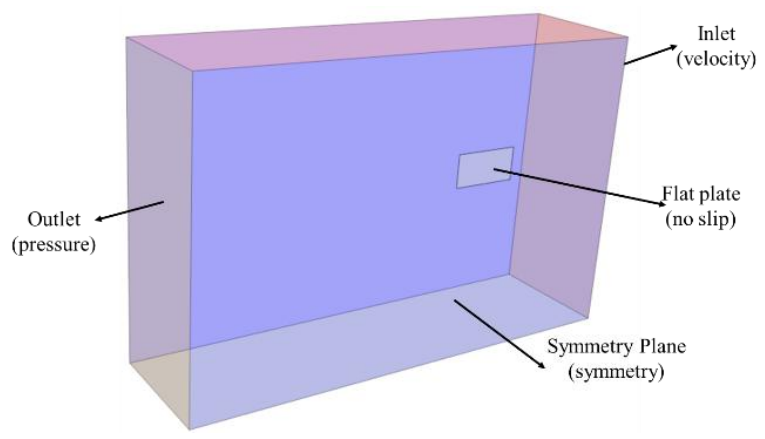

Fig. 3. Various boundary conditions used for the analysis

\section{Grid Independence Analysis}

A grid independence study is carried out to analyze the solution convergence. The cell grids are generated in STAR-CCM+ with trimmed hexahedral cells. Since the study involves the capturing of roughness characteristics of the anti-fouling coatings, it is important to precisely capture the 
boundary layer properties. To capture the boundary layer, additional near wall prism layers are imposed around the plate. The number and thickness of the prism layer affects the wall $\mathrm{Y}+$ function. The number of prism layers and prism layer thickness are determined and maintained at a value greater than 30 in order to use standard wall laws for all Reynolds numbers. Appropriate wall function and the solution convergence is obtained through the grid independence study.

The mesh is generated for four different prism layers and the change in wall Y+ is evaluated, See "Fig. 4". The number of prism layers is fixed at 10 for further analysis since the experimental value of $\mathrm{C}_{\mathrm{F}}$ and wall $\mathrm{Y}+$ is within the optimum range. Further, the effect of thickness of the prism layer is checked for four thickness values from the surface of the plate. The thickness of the prism layer is fixed at $0.015 \mathrm{~m}$ for the appropriate wall $\mathrm{Y}+$ function and the $\mathrm{C}_{\mathrm{F}}$ value, See "Fig. 5 ".

The Grid Convergence Index (GCI) Method based on Richardson extrapolation [21] is used to check the convergence of results. The values are within the standard limits and shown in "Table I".

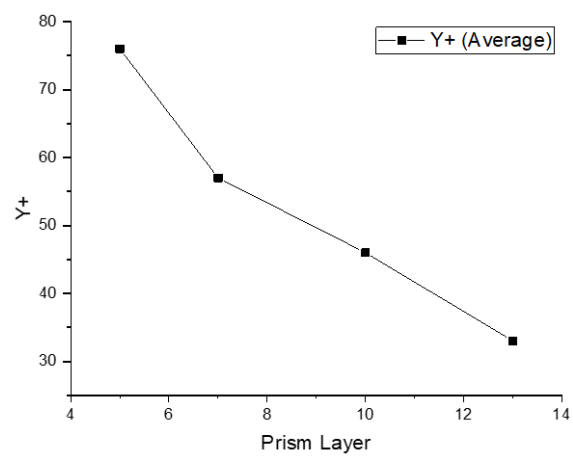

Fig. 4. Variation of wall y+ against number of prism layers

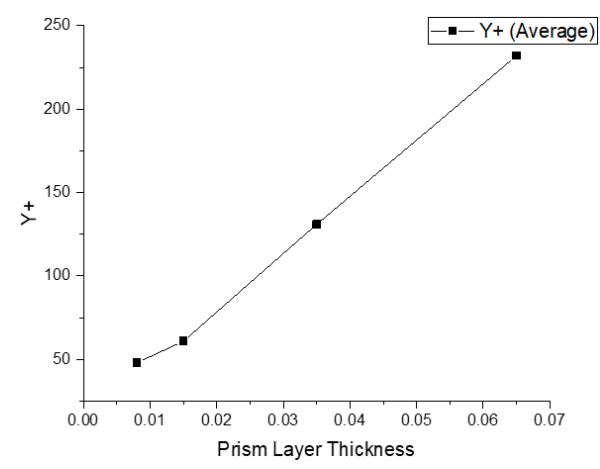

Fig. 5. Variation of wall y+ against prism layer thickness

A mesh density analysis is carried out on the plate with SPC TBT coating to validate the selected prism layer and thickness values. The results are analyzed in terms of the value of frictional coefficient and roughness Reynolds number k+. The values obtained are shown in "Table II" for four different cell sizes. It is observed that above 3 million cell size the variation of the results are minimal. Hence the computational setup with 3 million cells are selected for further studies.

Table- I: GCI of $\mathrm{C}_{\mathrm{F}}$ values for the plate

\begin{tabular}{|l|l|}
\hline & \multicolumn{1}{c|}{$\mathbf{C}_{\mathbf{F}}$} \\
& (with monotonic convergence) \\
\hline$r_{21}, r_{32}$ & $\sqrt{2}$ \\
\hline
\end{tabular}

\begin{tabular}{|l|l|}
\hline$\phi_{1}$ & 0.003792 \\
\hline$\phi_{2}$ & 0.003797 \\
\hline$\phi_{3}$ & 0.003816 \\
\hline$p$ & 0.8811 \\
\hline$\phi_{\text {ext }}^{21}$ & 0.003749 \\
\hline$e_{a}^{21}$ & $0.3687 \%$ \\
\hline$e_{\text {ext }}^{211}$ & $0.9014 \%$ \\
\hline$G C I_{\text {fing }}^{21}$ & $1.1126 \%$ \\
\hline
\end{tabular}

Table- II: $C_{F}$ results at different $y+$ values for the validation study

\begin{tabular}{|c|c|c|c|c|c|}
\hline Cell Size & $C_{F}(E F D)$ & $C_{F}$ (CFD) & Error & $\begin{array}{l}\text { k+ } \\
\text { (Eq. 8) }\end{array}$ & $\begin{array}{l}\text { Average } \\
\text { k+(CFD) }\end{array}$ \\
\hline $1 \times 10^{6}$ & \multirow{4}{*}{0.003783} & 0.003719 & $-1.72 \%$ & \multirow{4}{*}{0.260} & 0.270 \\
\hline $1.8 \times 10^{6}$ & & 0.003788 & $0.13 \%$ & & 0.270 \\
\hline $3.0 \times 10^{6}$ & & 0.003797 & $0.37 \%$ & & 0.265 \\
\hline $6.5 \times 10^{6}$ & & 0.003813 & $0.79 \%$ & & 0.265 \\
\hline
\end{tabular}

The mesh distribution on the computational domain is shown in "Fig. 6", where fine refinements are carried out around the plate and the free surface region. "Fig. 7" and "Fig. 8", shows mesh distribution in the $\mathrm{x}-\mathrm{z}$ plane and the mesh in the free surface region. The prism layer distribution around the plate is shown in "Fig. 9".

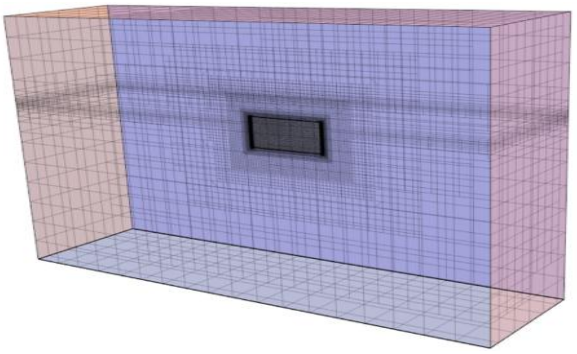

Fig. 6. Mesh distribution on the computational domain

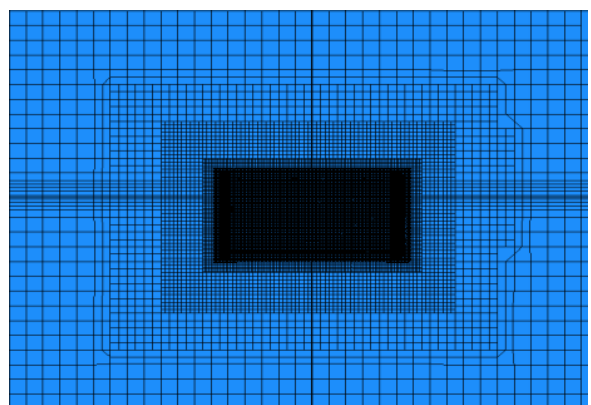

Fig. 7. Mesh distribution on $x-z$ plane

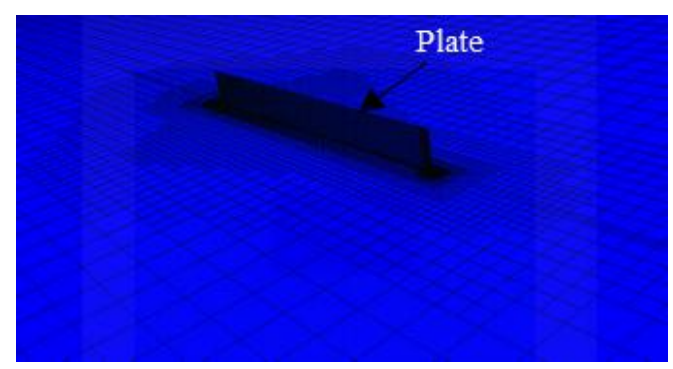

Fig. 8. Refined mesh in the free surface region 


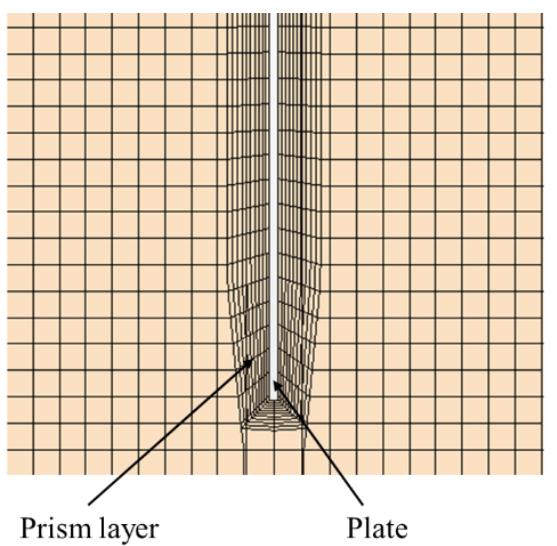

Fig. 9. Prism layer distribution around the plate

"Fig. 10", shows the wall Y+ values for the smooth plate at all three Reynolds numbers. The wall Y+ values are maintained same for all rough condition simulations.

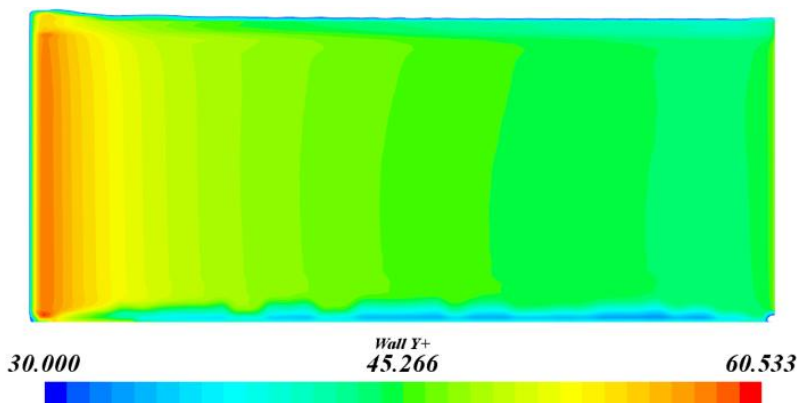

(a)

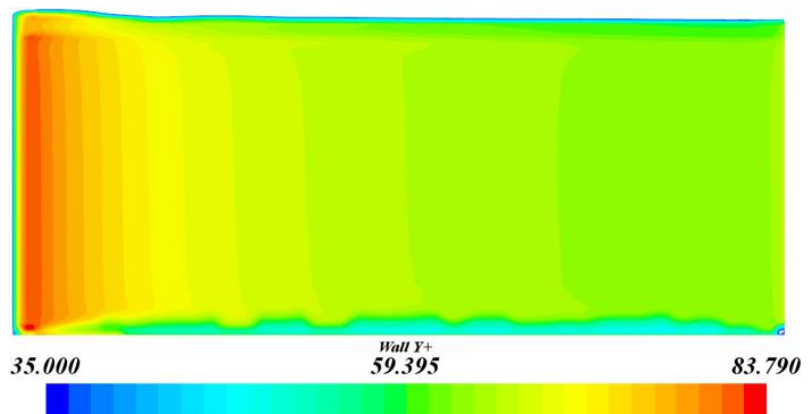

(b)

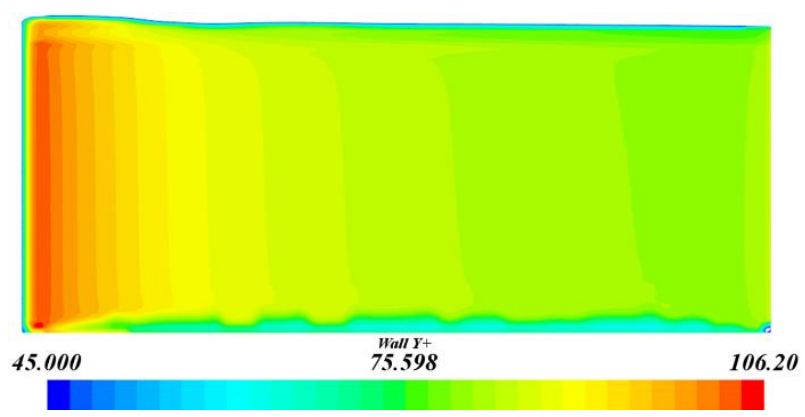

(c)

Fig. 10. Wall $y+$ on the smooth plate (a) Case 1, $\operatorname{Re}=2.8 \times 10^{6}$, (b) Case 2, $\operatorname{Re}=4.2 \times 10^{6}$, (c) Case 3, $\operatorname{Re}=5.5 \times 10^{6}$

\section{A. Estimation of Frictional Resistance}

Frictional resistance coefficients are computed and compared with experiments for smooth, sand paper and five different coatings such as silicon 1, silicon 2, ablative copper, SPC copper and SPC TBT $\mathrm{Re}=2.8 \times 10^{6}, \mathrm{Re}=4.2 \times 10^{6}$ and $\mathrm{Re}=5.5 \times 10^{6}$ respectively. As the roughness amplitude increases, the $\mathrm{CF}$ values also increases but decreases with the increase in Reynolds's number. The effect of roughness and Reynolds number has been clearly captured by the CFD solver. "Fig.11" to "Fig.13", shows the comparison results of CFD and experimental for various anti-fouling coating at three different Reynolds number. The same computational setup and roughness conditions are used to generate and analyze the sand paper roughness for the plate, and hence it has been observed that the error percentage is slightly more than all other rough cases. "Fig.14", depicts the comparison of the result for sand paper case. For all cases, the comparison of friction coefficient values using CFD is well matched with the EFD results, See "Fig.15".

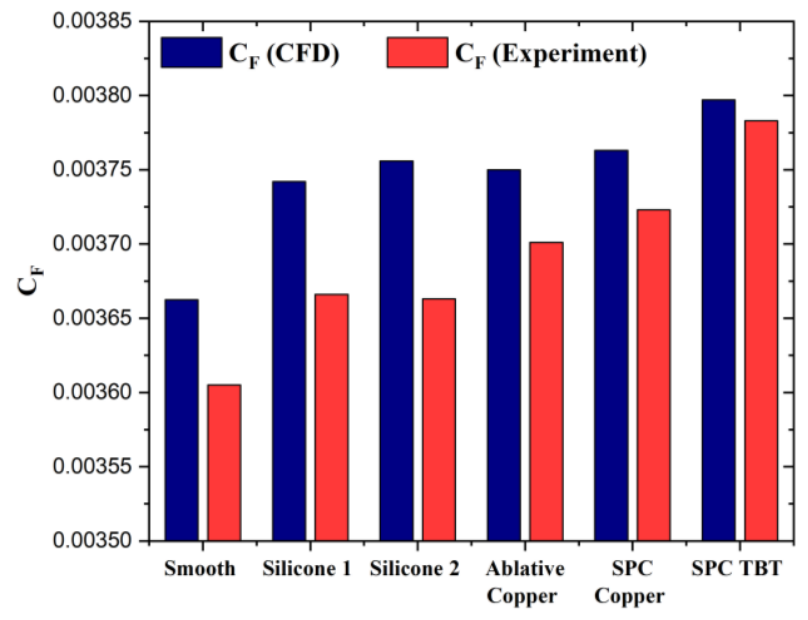

Fig. 11. Validation of CFD with EFD results for $\mathrm{Re}=$ $2.8 \times 10^{6}$

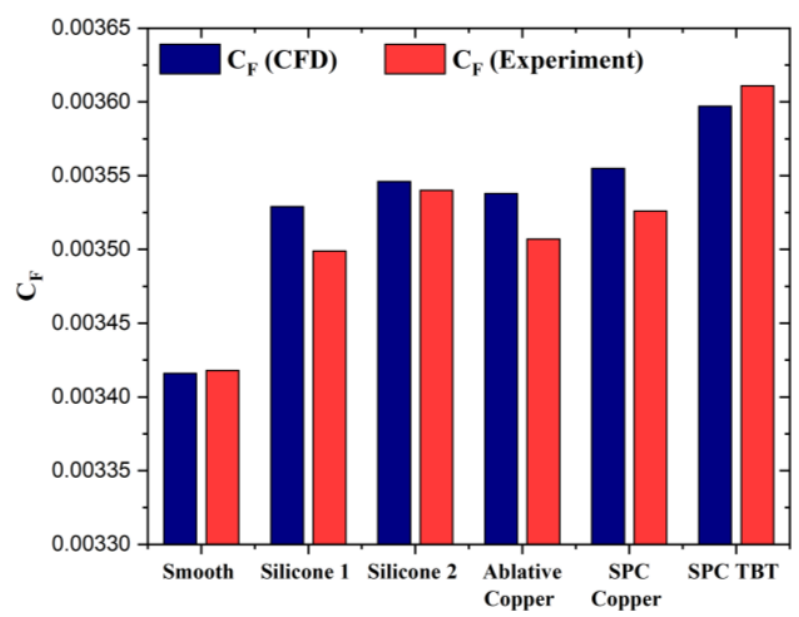

Fig. 12. Validation of CFD with EFD results for $\operatorname{Re}=4.2 \times 10^{6}$

III. RESULTS AND DISCUSSION 


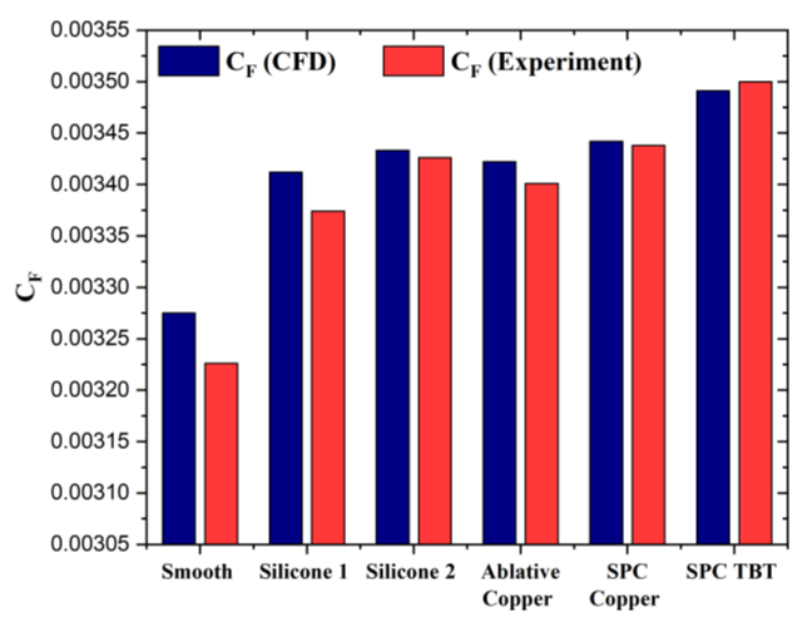

Fig. 13. Validation of CFD with EFD results for $\operatorname{Re}=5.5 \times 10^{6}$

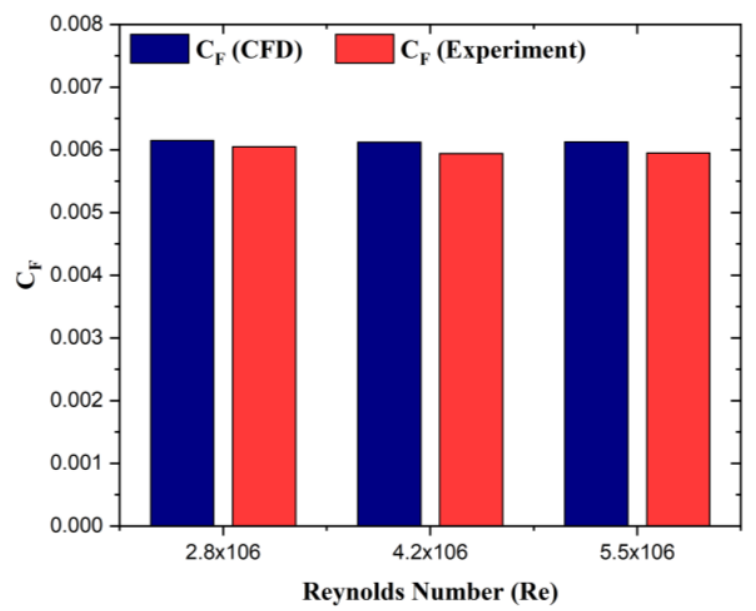

Fig. 14. Validation of CFD with EFD for 60 grit sand paper

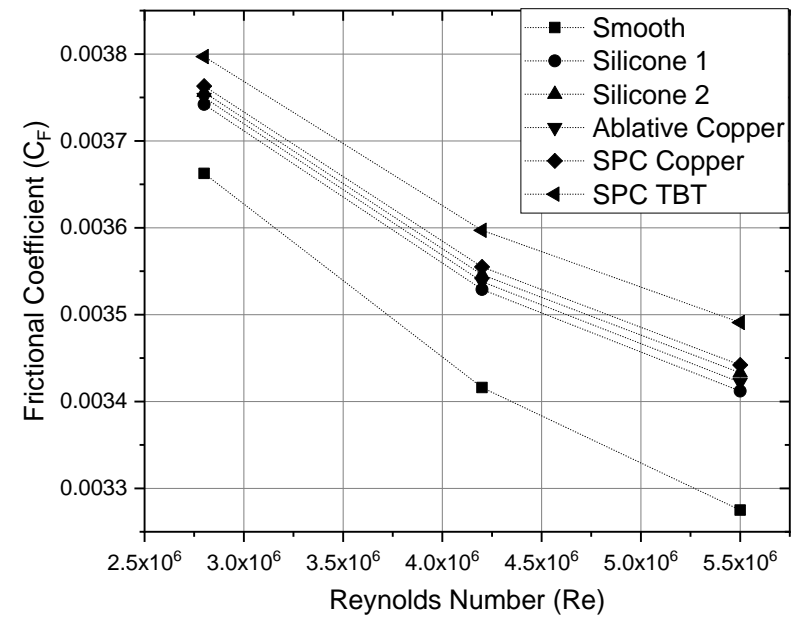

Fig.15. Comparison of CFD results for all anti-fouling coatings against smooth case

\section{B. Estimation of Roughness Condition}

Accurate roughness condition can be implemented with the knowledge of $k+$. It is reported that the $k+$ value should be always lesser than the $\mathrm{y}+$ values. The values of roughness condition is simulated in CFD to check the roughness parameter on the surface of the plate with the experimental values. The Reynolds roughness number, $k+$ is calculated using the Eq. 1 using the experimental $\mathrm{C}_{\mathrm{F}}$ values. The $k+$ distribution on the surface of the plate obtained from the CFD is verified with the calculated values. A typical distribution of $k+$ for SPC TBT is shown in "Fig.16".

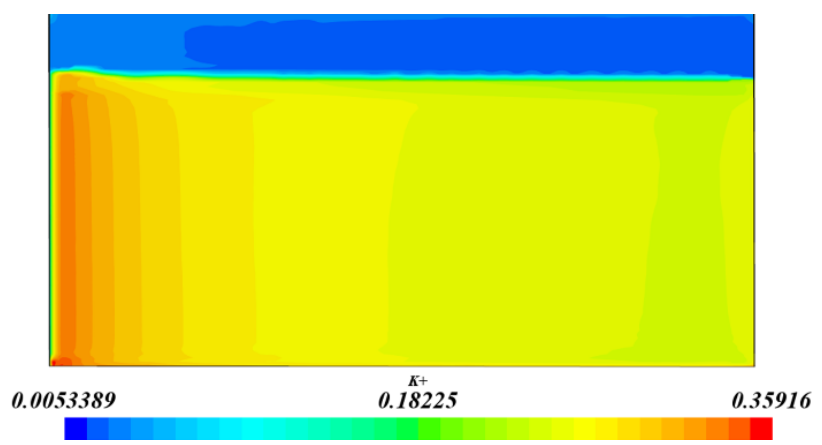

(a) $\operatorname{Re}=2.8 \times 10^{6}$

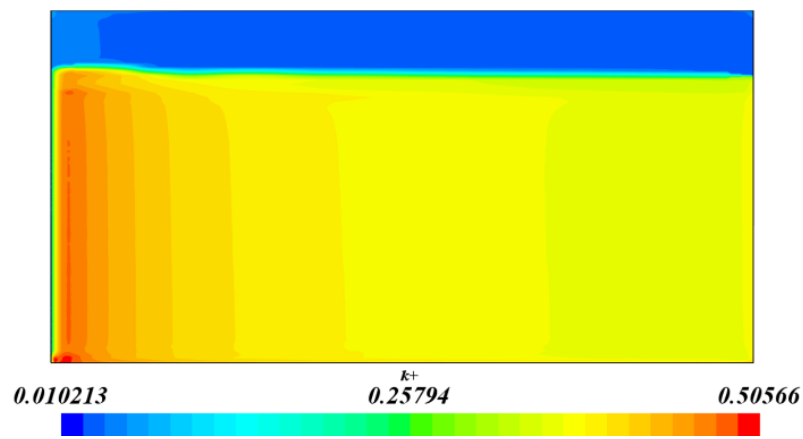

(b) $\operatorname{Re}=4.2 \times 10^{6}$

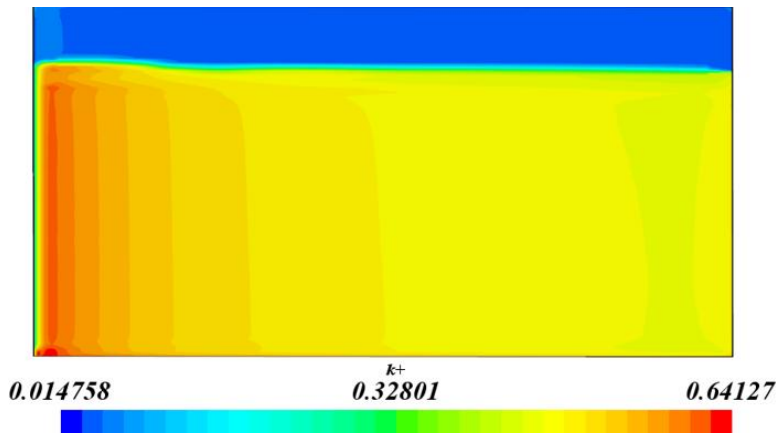

(c) $\operatorname{Re}=5.5 \times 10^{6}$

Fig.16. CFD results on roughness distribution

The most frequently occurring roughness Reynolds numbers are tabulated from the CFD results and compared with the experimental data. The comparison for all the Reynolds numbers are shown in "Fig. 17". 


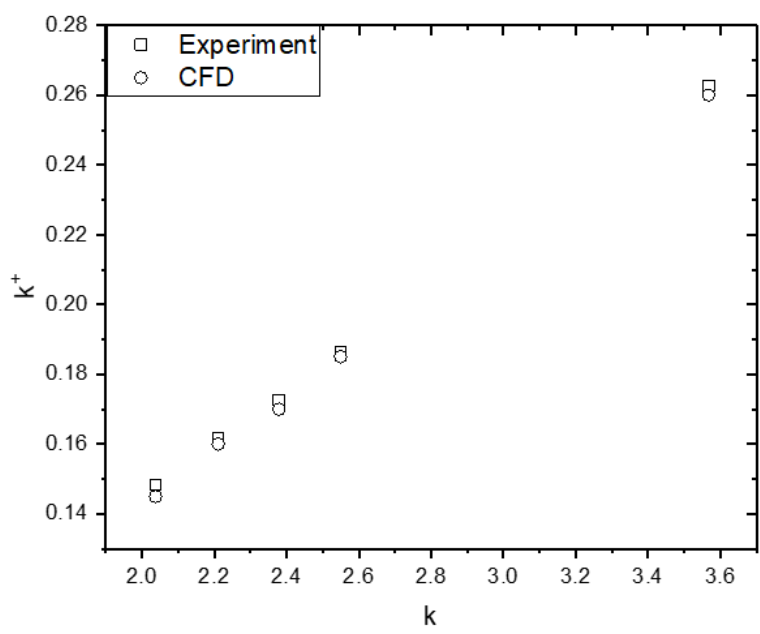

(a) $\operatorname{Re}=2.8 \times 10^{6}$

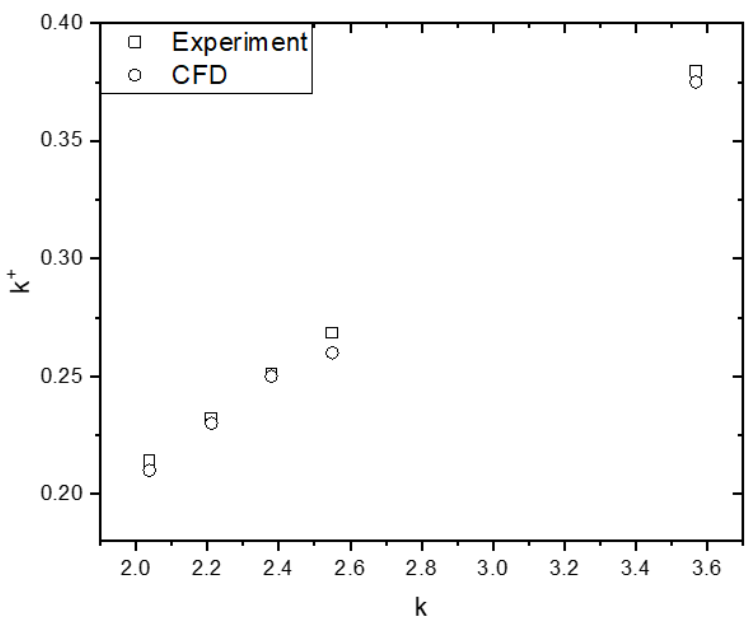

(b) $\quad \operatorname{Re}=4.2 \times 10^{6}$

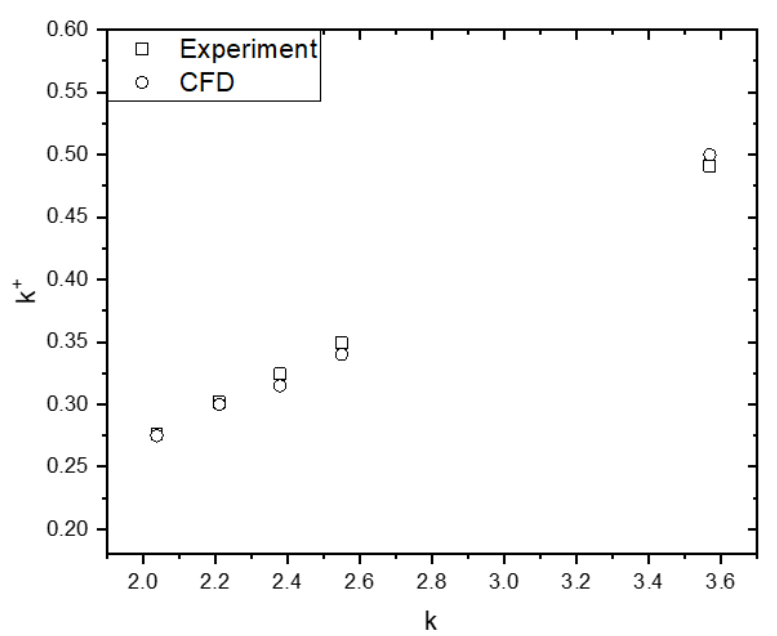

(c) $\quad \operatorname{Re}=5.5 \times 10^{6}$

Fig. 17. Comparison of roughness amplitude parameter against roughness Reynolds number

With the obtained CFD results, an analysis has been carried out to study the percentage increase in the frictional coefficient for the anti-fouling coatings at $\mathrm{Re}=2.8 \times 10^{6}, \mathrm{Re}=$ $4.2 \times 10^{6}$ and $\mathrm{Re}=5.5 \times 10^{6}$, See "Fig. 18", "Fig. 19" and "Fig. 20 ". This analysis may help in the selection of anti-fouling coating for the ship hull.

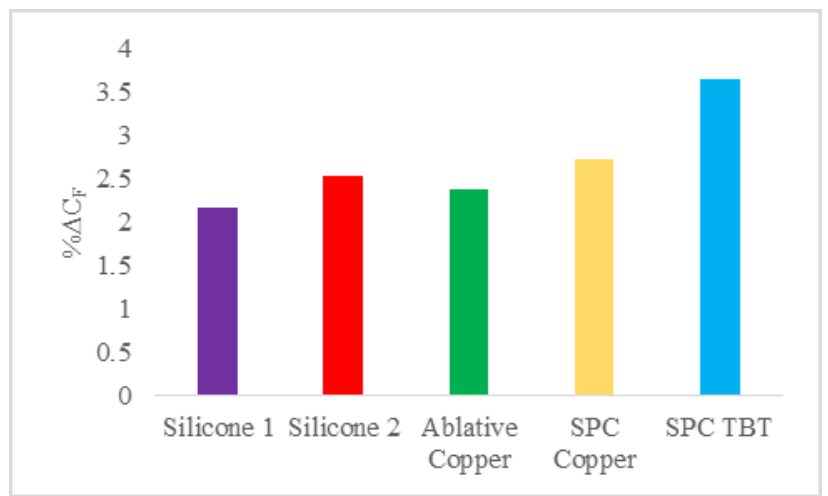

Fig. 18. Change in Frictional Resistance $\left(C_{F}\right)$ value at $\operatorname{Re}=2.8 \times 10^{6}$

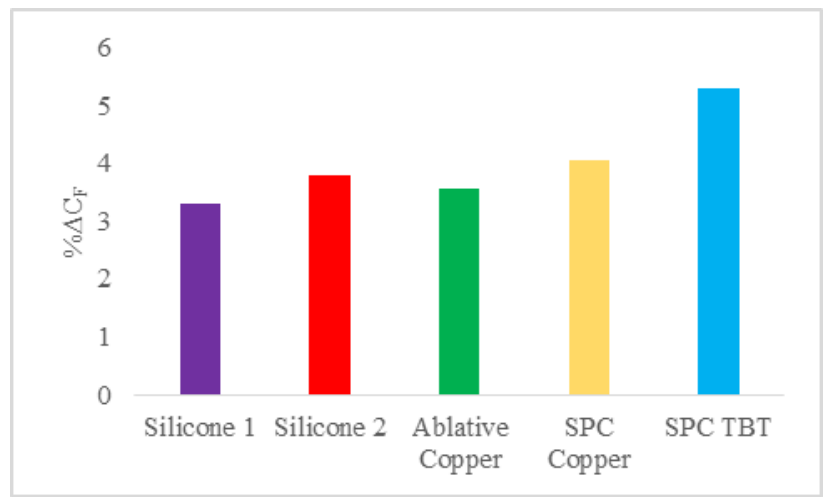

Fig. 19. Change in Frictional Resistance $\left(C_{F}\right)$ value at $\operatorname{Re}=4.2 \times 10^{6}$

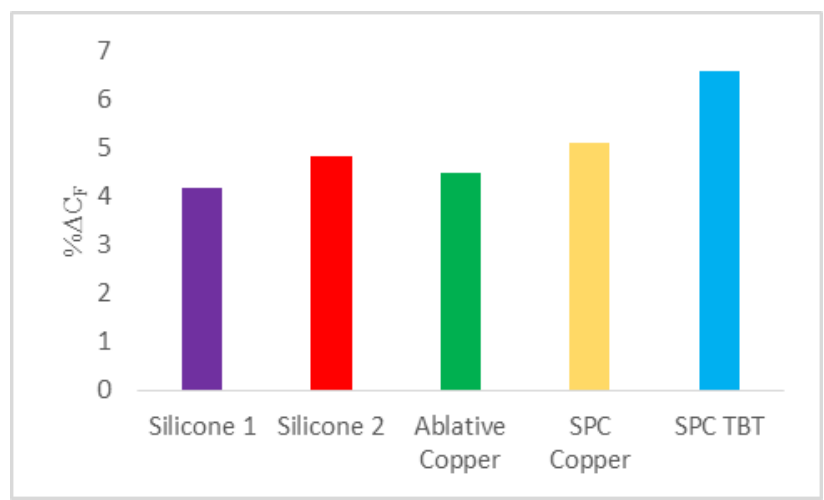

Fig. 20. Change in Frictional Resistance $\left(C_{F}\right)$ value at $\operatorname{Re}=5.5 \times 10^{6}$

The value of turbulent kinetic energy and the change in velocity magnitude are captured to check the influence of roughness due to anti-fouling coatings. It has been observed that turbulent kinetic energy and the velocity magnitude has a drastic variation when compared with the smooth and SPC TBT conditions. The effect of these two parameters are shown in "Fig. 21" and "Fig. 22", respectively. 


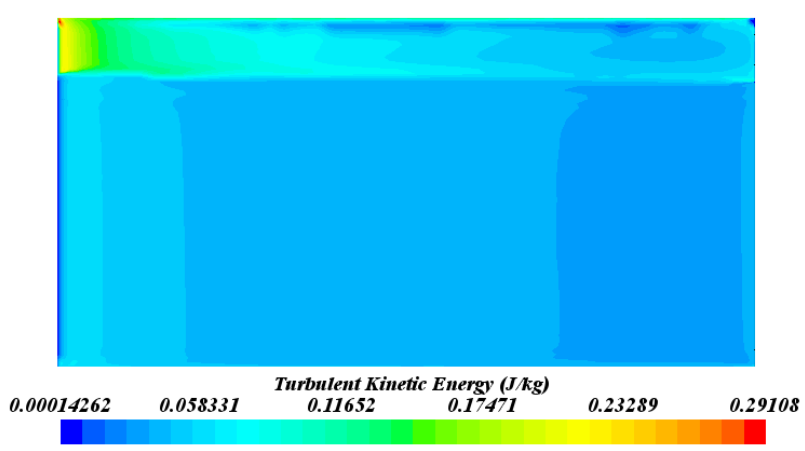

(a) Smooth

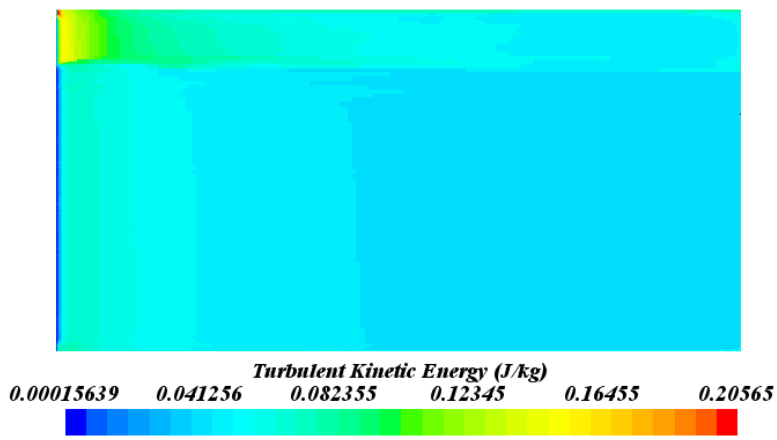

(b) SPC TBT

Fig. 21. Effect of turbulent kinetic energy for smooth and SPC TBT conditions at $\operatorname{Re}=2.8 \times 10^{6}$

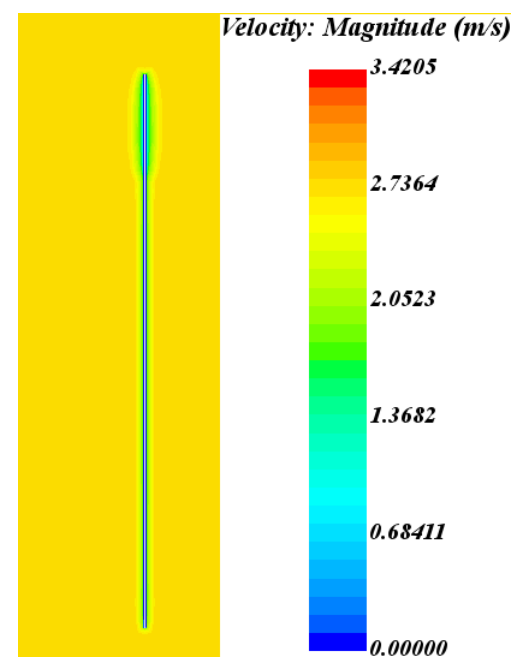

(a) Smooth

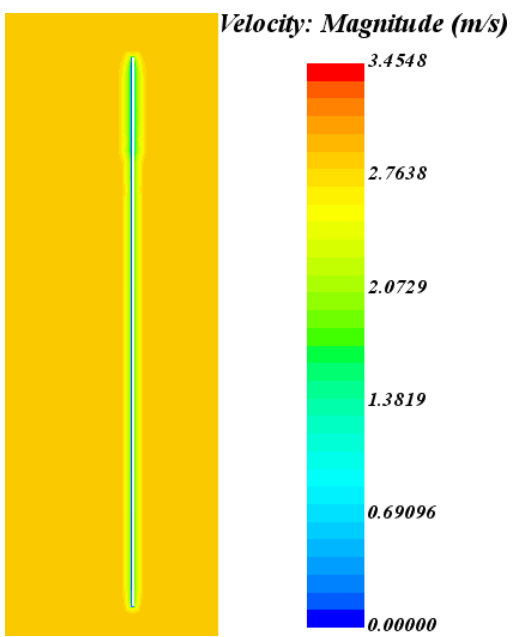

(b) SPC TBT

Fig. 21. Variation in velocity magnitude for smooth and SPC TBT conditions at $\operatorname{Re}=2.8 \times 10^{6}$

\section{CONCLUSION}

The paper discusses the CFD analysis on a flat plate to estimate the roughness effect due to various marine anti-fouling coatings. To replicate the roughness condition to match the Colebrook-type roughness function a roughness height, $k$ for antifouling surface as $0.17 R_{a}$ for un-fouled conditions $0.75 R_{t}$ for sand paper roughness. The results obtained are well matched with the experiments and the error percentage falls between 0.12 to $3.00 \%$. The variation in the percentage difference may be due to implementing the same roughness parameters for all cases. The work presented here would be used in ship hulls, where the hull is considered as a flat plate for evaluating the frictional component. It has been observed that the frictional resistance of the case with SPC TBT has higher $\mathrm{C}_{\mathrm{F}}$ values than other coating surfaces. The CFD method adopted here with the antifouling coatings are capable of predicting the real values of frictional resistance, with the applied roughness function model. The work can be extended to estimate the frictional resistance, and hence the powering characteristics for ships with anti-fouling coatings or various fouling conditions.

\section{REFERENCES}

1. IMO. (2014): Annex 5, Resolution MEPC.245 (66), 2014 Guidelines on the method of calculation of the attained Energy Efficiency Design Index (EEDI) for new ships.

2. IMO. (2012: Annex 9, Resolution MEPC.213 (63), 2012 Guidelines for the development of a Ship Energy Efficiency Management Plan (SEEMP).

3. IMO. (2009): MEPC 59/4/15, Prevention of air pollution from ships, Energy Efficiency Operational Indicator (EEOI)

4. IMO (2009): Second IMO GHG Study.

5. ITTC (2017): The Specialist Committee on Energy Saving Methods, Final Report and Recommendations to the 28 th ITTC

6. Kempf, G. (1937): On the effect of roughness on the resistance of ships. Trans INA, 79, 109-119

7. Lackenby, H. (1962): Resistance of ships with special reference to skin friction and hull surface condition, The 34th Thomas Lowe Grey Lecture, Proceedings of the Institute of Mechanical Engineers, Vol. 176, pp. $981-1014$ 
8. Schultz, M. P. \& Swain, G. (1999): The effect of biofilms on turbulent boundary layers. Journal of Fluids Engineering, 121, 44-51.

9. Taylan, M. (2010): An overview: effect of roughness and coatings on ship resistance. International Conference on Ship Drag Reduction SMOOTH-SHIPS

10. Schultz, M. P. \& Flack, K. (2007). The rough-wall turbulent boundary layer from the hydraulically smooth to the fully rough regime. Journal of Fluid Mechanics, 580, 381-405.

11. Townsin, R. L. (2003): The Ship Hull Fouling Penalty. Biofouling, 19, 9-15.

12. Lewkowicz, A. \& Das, D. (1986): Turbulent boundary layers on rough surfaces with and without a pliable overlayer: a simulation of marine fouling. International Shipbuilding Progress, 33, 174-186.

13. Schultz MP (2004): Frictional Resistance of Antifouling Coating Systems, [DOI:10.1115/1.1845552]

14. Grigson, C. (1992): Drag losses of new ships caused by hull finish. Journal of Ship Research, 36, 182-196.

15. Mizzi, K., Kellett P., Demirel, Y.K., Martin, R., Turan, O. (2015): HPC and CFD in the marine industry: past, present and future.

16. Patel, V. C. (1998): Perspective: Flow at high reynolds number and over rough surfaces-Achilles heel of CFD. Journal of Fluids Engineering, 120, 434-444

17. Demirel Y K, Khorasanchi M, Turan O, Incecik A Schultz MP. (2014): A CFD model for the frictional resistance prediction of antifouling coatings

18. Granville, P. S. (1958): The frictional resistance and turbulent boundary layer of rough surfaces. Journal of ship research, 2, 52-74.

19. Granville, P. S. 1987. Three indirect methods for the drag characterization of arbitrarily rough surfaces on flat plates. Journal of Ship Research, 31, 70-77.

20. Cebeci, T. \& Bradshaw, P. 1977. Momentum Transfer in Boundary Layers, Hemisphere Publishing Corporation/McGraw-Hill.

21. Celik, I. B., Ghia, U., Roache, P. J., Freitas, C. J., Coleman, H. \& Raad, P. E. 2008. Procedure for estimation and reporting of uncertainty due to discretization in CFD applications. Journal of Fluids Engineering-Transactions of the ASME, 130, 078001-1-4.

\section{AUTHORS PROFILE}

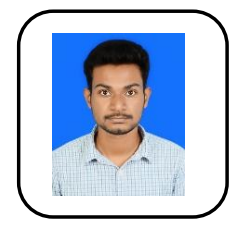

K. Abhiroop is currently pursuing undergraduate programme in Naval Architecture and Offshore Engineering from Academy of Maritime Education and Training, AMET deemed to be University, Chennai. He has published 3 articles in various journals and International conferences. His work on the application of CFD in ship hydrodynamics has been selected for the best paper in the international forum, 2018. He is an active student member of Marine Technology Society (MTS), U.S.A and Royal Institute of Naval Architects (RINA), London, U.K. He has attended various academic competitions conducted by various institutes around India and appreciated for his active participation.

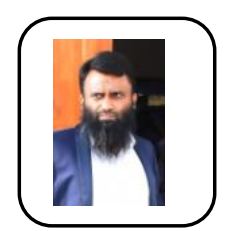

Dr.B.M. Shameem is currently working as assistant professor at Academy of Maritime Education and Training, AMET deemed to be University, Chennai. He has obtained his doctorate in Ocean Engineering from IIT Madras, India. He has been awarded as the best faculty for the 2017 and 2019 in AMET University for the usage of technology in teaching. His area of interest is on experimental and numerical ship hydrodynamics. He has published more than 10 publications in various journals and conferences. 